\title{
THE INTERACTION OF OXYGEN AND CARBON MONOXIDE WITH A CARBIDED Ni(111) SURFACE
}

\author{
T.J. VINK, M.M.J. VAN ZANDVOORT, O.L.J. GIJZEMAN and J.W. GEUS \\ Van 't Hoff Laboratory for Physical and Colloid Chemistry, State University of Utrecht, Padualaan 8 , \\ $3584 \mathrm{CH}$ Utrecht, The Netherlands
}

Received 5 December 1983; accepted for publication 20 March 1984

The thermal decomposition of ethylene on $\mathrm{Ni(111)}$ at $250^{\circ} \mathrm{C}$ is shown to lead to carbon deposition on and - in a later stage - below the surface. Independent of the amount of carbon below the surface, $\mathrm{CO}$ is adsorbed with an isosteric heat of adsorption of $105 \mathrm{~kJ} / \mathrm{mol}$. The surface carbon reacts with oxygen at $250^{\circ} \mathrm{C}$. The reaction rate is independent of the surface carbon coverage and first order in oxygen pressure. The subsurface carbon segregates to the surface after removal of the surface carbon layer.

\section{Introduction}

In this paper we study the interaction of ethylene with Ni(111), using Auger electron spectroscopy (AES) and ellipsometry. Since the latter technique allows an analysis of deeper layers as well, it complements earlier work on this system using low energy electron diffraction (LEED) $[1,2]$ or vibrational spectroscopy [3].

The reactivity of the carbide layer towards oxygen has been studied for $\mathrm{Ni}(100) / \mathrm{C}[4,5]$ and $\mathrm{Ni}(110) / \mathrm{C}[6]$. In the present work the same reaction for $\mathrm{Ni}(111)$ is studied and compared with the results obtained for the other two crystal faces.

The adsorption of $\mathrm{CO}$ on carbon covered nickel surfaces has been reported using electron loss spectroscopy for $\mathrm{Ni}(111)$ [7] and thermal desorption [8] for $\mathrm{Ni}(110)$. In this work we report the measurement of the actual adsorption isotherms, which is possible due to the non-destructive nature of ellipsometry.

\section{Experimental}

The experiments were carried out on a Ni(111) single crystal, mounted in a Varian UHV system, described previously [4]. Simultaneous Auger electron

0378-5963/84/\$03.00 @ Elsevier Science Publishers B.V. (North-Holland Physics Publishing Division) 
spectroscopy and ellipsometry were possible. Auger spectra were recorded in a derivative mode $E \mathrm{~d} N(E) / \mathrm{d} E$, using a cylindrical mirror analyser. With the ellipsometer, only off-null irradiance measurements were performed. The base pressure was about $4 \times 10^{-10}$ Torr. The cleaning procedure consisted of sputtering in an argon atmosphere of ca. $5 \times 10^{-5}$ Torr until AES indicated the surface to be clean, followed by annealing the crystal at $600^{\circ} \mathrm{C}$ for ca. 10 min. The gases used, $\mathrm{CO}$ (purity 99.99\%), $\mathrm{C}_{2} \mathrm{H}_{4}$ (purity 99.95\%), $\mathrm{O}_{2}(99.95 \%$ ) and $\operatorname{Ar}(99.999 \%)$, were supplied by l'Air Liquide.

\section{Results and discussion}

\subsection{The formation of the carbide layer}

The formation of the carbide layer on $\mathrm{Ni}(111)$ by thermal decomposition of ethylene at a crystal temperature of $250^{\circ} \mathrm{C}$ and a pressure of $3 \times 10^{-7} \mathrm{Torr}$, is given in fig. 1 . This typical reaction curve shows the enormous difference in time required to complete the two stages of deposition, which each involve a change of $0.2^{\circ}$ in $\delta \Delta$. Up to a carbon coverage, corresponding to $\delta \Delta=0.2^{\circ}$, the reaction curve scales with the ethylene exposure. The deposition of carbon at coverages above $\delta \Delta=0.2^{\circ}$ is more complicated.

A plot of the carbon AES peak height as a function of the ellipsometric parameter $\delta \Delta$, as given in fig. 2 , shows that the first change of $0.2^{\circ}$ in $\delta \Delta$ due to carbon deposited is linear with the carbon AES peak height, while during the second change in $\delta \Delta$ of $0.2^{\circ}$ there is no further increase in the AES signal beyond $h_{\mathrm{C}} / h_{\mathrm{Ni}}=0.16$. The difference between the two deposition stages can be explained by taking into consideration the different influence of the carbon layer on and just below the surface on the Auger and ellipsometric signal.

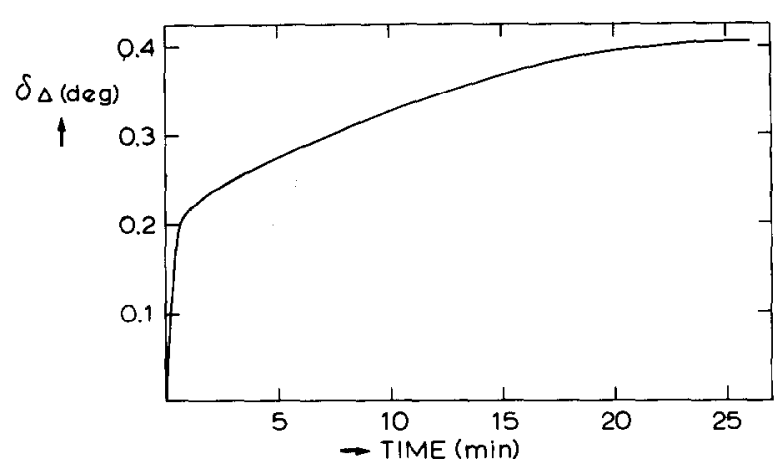

Fig. 1. Representative reaction curve of the decomposition of ethylene on $\mathrm{Ni}(111)$ at $250^{\circ} \mathrm{C}$, expressed as $\delta \Delta$ versus time. 


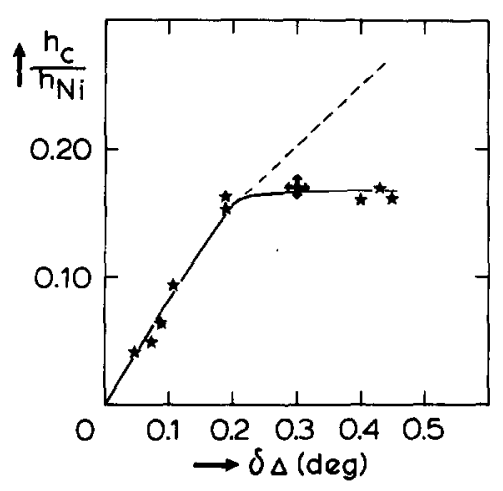

Fig. 2. Plot of the relative carbon Auger signal $h_{\mathrm{C}}(272 \mathrm{eV}) / h_{\mathrm{Ni}}(848 \mathrm{eV})$ as a function of $\delta \Delta$ at $250^{\circ} \mathrm{C}$. ( - _ - Model with half a monolayer on top of the surface and an equal amount of carbon just below it. (- Model with half a monolayer on top of the surface and a solubility-concentration in each of the layers below it. In both cases the curve up to $\delta \Delta=0.2^{\circ}$ is scaled with the experimental data.

Labohm et al. [5] concluded that a relative carbon AES peak height of 0.17 corresponds with half a monolayer of carbon on a Ni(100) surface. Taking the nickel AES peak height to be independent of the surface structure and the surface densities of the $\mathrm{Ni}$ atoms on a $\mathrm{Ni}(100)$ and a $\mathrm{Ni}(111)$ surface to be $1.61 \times 10^{19}$ and $1.86 \times 10^{19} \mathrm{~m}^{-2}$ respectively, half a monolayer of carbon on a $\mathrm{Ni}(111)$ surface would have to result in $h_{\mathrm{c}} / h_{\mathrm{Ni}}=0.20$. Using this number, the carbon coverage that corresponds with the ellipsometric signal $\delta \Delta=0.2^{\circ}$, and thus with $h_{\mathrm{C}} / h_{\mathrm{Ni}}=0.16$, must have a value around $\theta_{\mathrm{C}}=0.4$.

The further change in $\delta \Delta$ at constant $h_{\mathrm{C}} / h_{\mathrm{Ni}}$ is not simply a consequence of

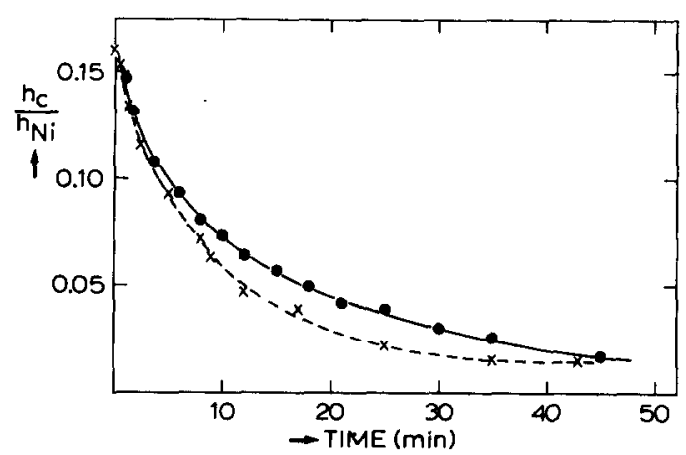

Fig. 3. The relative carbon Auger peak height $h_{\mathrm{C}} / h_{\mathrm{Ni}}$ as a function of the sputter time at room temperature, with carbide surfaces containing a carbon coverage of respectively $\left.0.2^{\circ} \delta \Delta(--)^{-}\right)$ and $0.4^{\circ} \delta \Delta(\longrightarrow)$. 
a change in electronic properties of the carbon adlayer. As shown in fig. 3 the sputter profiles for $\mathrm{Ni}(111)$ surfaces containing carbon up to $\delta \Delta=0.2^{\circ}$ and $\delta \Delta=0.4^{\circ}$ show that the latter system does indeed contain more carbon atoms, presumably located beneath the surface. The Auger intensity of such a system will be proportional to $X_{\mathrm{C}}$, where $X_{\mathrm{C}}$ is given by [9]:

$X_{C}=c_{1}+\left(c_{2}-c_{1}\right) \exp (-z / D)+\left(c_{3}-c_{2}\right) \exp (-2 z / D)+\ldots$,

and $c_{i}$ are the molfractions of carbon in layer $i$. The interlayer spacing is $z$ and $D$ is related to the mean escape depth $\lambda$ via [10]

$D=\lambda \cos \left(42^{\circ}\right)=0.75 \lambda$.

In our calculations we have used $\lambda=6.3 \AA$ [11] and $z=2.03 \AA$.

Scaling the surface coverage to the observed relation between $\delta \Delta_{C}$ and $h_{\mathrm{C}} / h_{\mathrm{Ni}}$ (fig. 2), this approach leads to the dotted curve, when the deposition steps are equally divided between the first and the second atomic layer. The assumption that the first and second layer contain eventually the same amount of carbon is thus inadequate to explain the observed curve shown in fig. 2. Thus the carbon deposition must be different putting carbon in deeper layers.

Another obvious possibility is that carbon is equally distributed in the layers below the surface, each having a concentration given by the solubility of carbon in $\mathrm{Ni}$ at $250^{\circ} \mathrm{C}$. The carbon solubility extrapolated from data reported by Natesan and Kassner [12] has a value of $3.2 \times 10^{-3} \mathrm{~mol} \mathrm{C} / \mathrm{mol} \mathrm{Ni}$. Putting as much carbon beneath the surface as on top of it, about 130 atomic layers must have such a carbon concentration.

A surface concentration of 0.4 and a concentration of $3.2 \times 10^{-3}$ in each of the underlaying layers is used in eq. (1) to calculate the carbon AES peak height, which resulted in a good fit with the experimental data as shown in fig. 2.

\subsection{The reaction of the carbide layer on $N i(111)$ with oxygen}

In order to obtain a quantitative interpretation of the rather complex reaction curves, concerning the interaction between the carbide layer and oxygen, we started by measuring the correlation between the oxygen AES peak height and the ellipsometric parameter $\delta \Delta$ on a clean Ni(111) surface. This is shown in fig. 4, which is in agreement with the results of Labohm et al. [13]. The initial increase in $\delta \Delta$ of $0.1^{\circ}$ is due to to chemisorbed oxygen which precedes the incorporation of oxygen $[13,14]$.

At a crystal temperature of $250^{\circ} \mathrm{C}$ and an oxygen pressure of $3 \times 10^{-7} \mathrm{Torr}$, the interaction of oxygen with the carbide layer, containing different carbon coverages, is represented in fig. 5 . The initial increase in the ellipsometric signal in the reaction curves of fig. $S$ is due to adsorption of chemisorbed oxygen since the removal of carbon from the surface decreases the value of $\delta \Delta$ (cf. fig. 

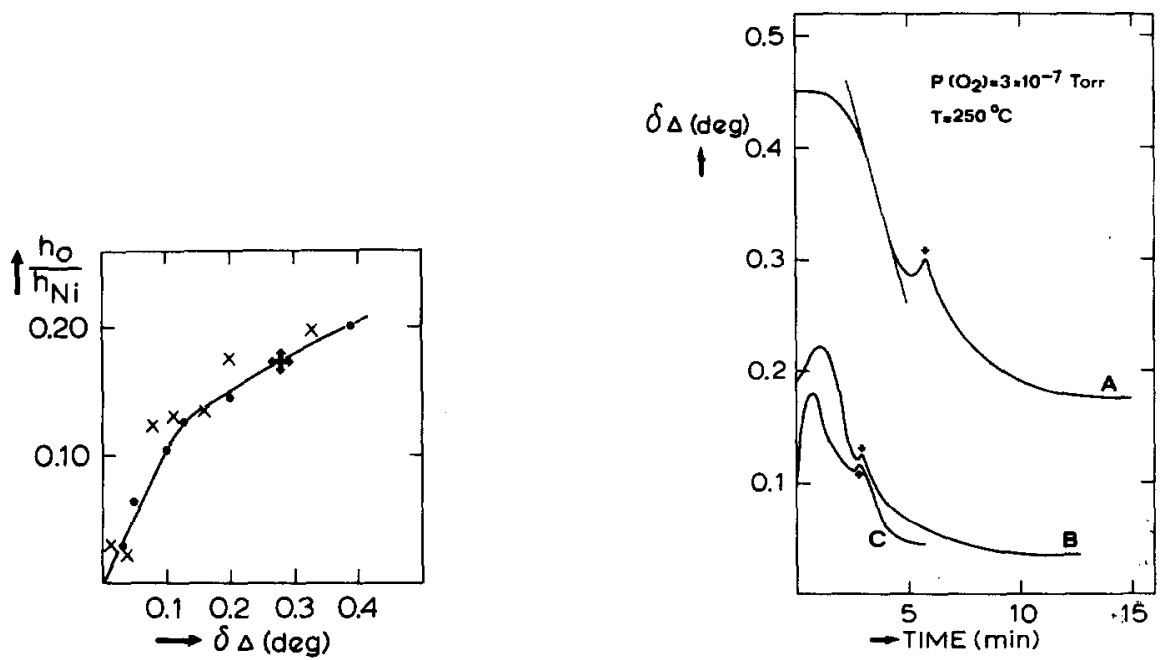

Fig. 4. Plot of the relative oxygen Auger peak height $h_{\mathrm{O}}(515 \mathrm{eV}) / h_{\mathrm{Ni}}(848 \mathrm{eV})$ as a function of $\delta \Delta$ at $250^{\circ} \mathrm{C}(\bullet) ;(\times)$ after exposing the carbide layer on $\mathrm{Ni}(111)$ to oxygen leaving only oxygen on the surface at $250^{\circ} \mathrm{C}$.

Fig. 5. Interaction of oxygen, $p\left(\mathrm{O}_{2}\right)=3 \times 10^{-7}$ Torr, with the carbide layer on $\mathrm{Ni}(111)$, containing different carbon coverages. The arrows placed at the reaction curves indicate the time at which the system was evacuated. The solid line in the upper reaction curve indicates the reaction rate in the proposed mechanism. Starting carbon coverages of 0.45 (A), 0.19 (B) and 0.10 (C) in $\delta \Delta$.

2). Thus the reaction of oxygen with carbon is relatively slow in comparison with the oxygen uptake at a pressure of $3 \times 10^{-7}$ Torr. The amount of chemisorbed oxygen in the initial stage depends on the carbon coverage, as can be seen from fig. 5 , less oxygen being adsorbed as more carbon is present. Further exposure of the carbide layer to oxygen results in a decrease in $\delta \Delta$, caused by the removal of carbon from the surface which outweighs the simultaneous adsorption of chemisorbed oxygen. This relatively linear part of the reaction curve is followed by an increase in $\delta \Delta$ due to incorporation of oxygen.

At the start of the incorporation stage, just beyond the minimum value of $\delta \Delta$, the system was evacuated, which is indicated by the arrows placed at the reaction curves. Despite the absence of gaseous oxygen, the reaction continues to remove both oxygen and carbon from the surface, as indicated by the decrease in $\delta \Delta$ and verified by AES, until only oxygen or a clean surface remains. The amount of oxygen remaining on the surface, expressed in terms of AES peak heights is in the same way related to the ellipsometric parameter $\delta \Delta$ measured after reaction as oxygen directly adsorbed from $\mathrm{O}_{2}$. These data points are included in fig. 4. 
The interaction of the carbide layer, containing a fixed carbon coverage of $0.2^{\circ}$ in $\delta \Delta$, towards oxygen at different pressures is shown in fig. 6 . The reaction path can be qualitatively described as before, except for the oxygen pressure of $5 \times 10^{-8}$ Torr.

The initial reaction rate at the oxygen pressure of $5 \times 10^{-8}$ Torr indicates that adsorption of chemisorbed oxygen (increasing $\delta \Delta$ ) and the reaction with surface carbon (decreasing $\delta \Delta$ ) just compensate each other at the initial stage of the reaction curve. After evacuation just beyond the minimum value of $\delta \Delta$, the reaction cannot proceed because of the lack of surface carbon as indicated by AES. The oxygen remaining on the surface can be related to $\delta \Delta$ as was previously described. The reaction rate, calculated from the linear parts of the reaction curves, during oxygen exposure is first order in the oxygen pressure (from fig. 6) and independent of carbon coverage (from fig. 5). The initial reaction rate after evacuation appeared to be the same as that found during oxygen exposure.

The interaction of oxygen with the carbide layer can be evaluated by using a Langmuir-Hinshelwood scheme as previously used by Mesters et al. [15]:

$\mathrm{O}_{2}(\mathrm{~g}) \underset{k_{2}}{\stackrel{k_{1}}{\rightleftarrows}} \mathrm{O}_{2}(\mathrm{ad}) \underset{k_{4}}{\stackrel{k_{3}}{\rightleftarrows}} 2 \mathrm{O}(\mathrm{ad})$,

$\mathrm{O}_{\mathrm{ad}}+\mathrm{C}_{\mathrm{ad}} \stackrel{k_{5}}{\rightarrow} \mathrm{CO}_{\mathrm{ad}}$

$\mathrm{CO}_{\mathrm{ad}} \stackrel{k_{\mathrm{f}}}{\rightarrow} \mathrm{CO}_{\mathrm{g}}$

When the subsequent steps in the reaction scheme are relatively fast the observed reaction rate can be described by the following equation

$\mathrm{d}(\delta \Delta) / \mathrm{d} t=-k_{5} \mathrm{O}_{\mathrm{ad}} \mathrm{C}_{\mathrm{ad}}$.

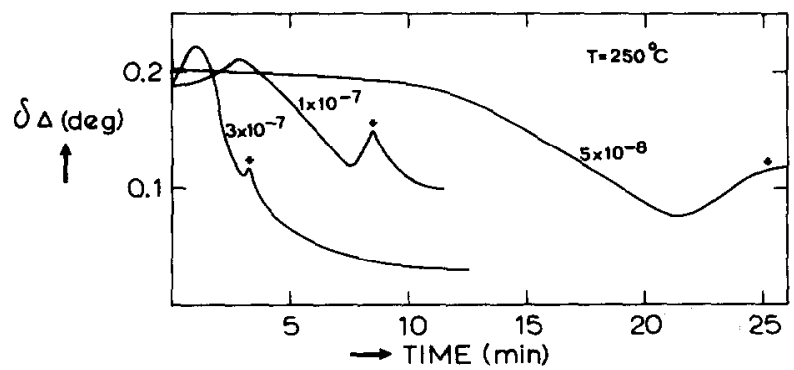

Fig. 6. Reaction curves for the removal of carbon from a Ni(111) surface, containing a carbon coverage of $0.2^{\circ}$ in $\delta \Delta$ for different oxygen pressures in Torr. The arrows indicate the evacuation of the system. 
Assuming a steady state for the oxygen surface species and $k_{4}=0$, eq. (6) can be written in terms of the carbon coverage

$\frac{\mathrm{d}(\delta \Delta)}{\mathrm{d} t}=-\frac{2 k_{1} k_{3}}{k_{2}+k_{3}} p\left(\mathrm{O}_{2}\right)=-K p\left(\mathrm{O}_{2}\right)$

The reaction rate in eq. (7) is thus first order in the oxygen pressure and independent of carbon converge, which is in agreement with the experimental observations. The same reaction on $\mathrm{Ni}(110)$ was also found to be first order in the oxygen pressure as reported by Sau and Hudson [6], but dependent on the carbon concentration. For $\mathrm{Ni}(100) / \mathrm{C}$, however, a $p^{1 / 2}$ dependence was found for low carbon coverages $\left(\theta_{c} \leqslant 0.25\right)$ [4], whereas for larger amounts of carbon a rather involved reaction scheme was necessary [5].

From the value of $K\left(=4.1 \times 10^{-40} / \mathrm{L}\right)$, the reaction probability, defined as the number of carbon atoms removed per incident oxygen atom, can be calculated. It is found to be $6 \times 10^{-2}$ at $250^{\circ} \mathrm{C}$. This number is independent of oxygen pressure and carbon coverage. From the data of Sau and Hudson on $\mathrm{Ni}(110) / \mathrm{C}$ a reaction probability of $8 \times 10^{-3}$ is obtained at $250^{\circ} \mathrm{C}$ for the start of the reaction. At lower carbon coverages this value decreases. It is, however, independent of the oxygen pressure. On $\mathrm{Ni}(100) / \mathrm{C}$ a reaction probability of $2 \times 10^{-3}$ can be deduced from the data [5]. This value is calculated for $\theta_{C}=0.2$ and $p\left(\mathrm{O}_{2}\right)=2 \times 10^{-7}$ Torr. It decreases with decreasing carbon coverage and is proportional to $p^{-1 / 2}$, as the reation rate itself is proportional to $p^{1 / 2}$. For comparable conditions the reactivity of carbon on nickel surfaces is thus in the order $(111)>(110)>(100)$. The three surfaces share the common feature that (at high carbon concentration) the reaction clearly involves loosely bound adsorbed oxygen, since the reaction proceeds in all cases as the gas pressure is removed.

\subsection{Segregation of carbon to the Ni(111) surface}

As has been stated previously (section 3.1) the carbide layer was partly situated below the surface, at carbon coverages above $0.2^{\circ}$ in, $\delta \Delta$. Using the fact that carbon situated below the surface cannot be detected by AES, the following experiment was carried out in order to measure carbon segregation. Starting with a carbon coverage of $0.4^{\circ}$ in $\delta \Delta$ the surface part of the carbide layer was removed by interaction with oxygen. The reaction path followed was analogous to the description given previously (section 3.2 ) and resulted in an almost clean surface. After the removal of the surface part of the carbide layer, the segregation of carbon was measured by AES as a function of time for different crystal temperatures, as given in fig. 7 .

Segregation isotherms can be described according to McLean [16], where $\theta$ 
is the surface molfraction and $x$ the bulk molfraction of carbon:

$$
\frac{\theta}{1-\theta}=\frac{x}{1-x} \exp \left(-\Delta G_{\mathrm{seg}} / k T\right) \text {. }
$$

The observed segregation rate can be evaluated in terms of surface and bulk concentration of carbon:

$\mathrm{d} \theta / \mathrm{d} t=k_{1} x(1-\theta)-k_{2} \theta(1-x)$.

Assuming the value of $\delta \Delta$ to be proportional to the total amount of carbon present, the reaction with oxygen removes $0.2^{\circ}$ in $\delta \Delta$ from the surface. This corresponds to $h_{\mathrm{C}} / h_{\mathrm{Ni}}=0.16$. Starting with an initial total carbon concentration of $\delta \Delta(0)$, the bulk concentration of carbon would give a hypothetical Auger intensity of

$\left(h_{\mathrm{C}} / h_{\mathrm{Ni}}\right)_{\mathrm{b}}=[\delta \Delta(0)-0.2] / 0.2 \times 0.16$.

At any time we then have:

$\theta=\left(h_{\mathrm{C}} / h_{\mathrm{Ni}}\right) /\left(h_{\mathrm{C}} / h_{\mathrm{Ni}}\right)_{\max }$,

$x=\left(h_{\mathrm{C}} / h_{\mathrm{Ni}}\right)_{\mathrm{b}}-\left(h_{\mathrm{C}} / h_{\mathrm{Ni}}\right)$,

$\left(h_{\mathrm{C}} / h_{\mathrm{Ni}}\right)_{\max }=0.16, \quad\left(h_{\mathrm{C}} / h_{\mathrm{Ni}}\right)_{\mathrm{b}}=[\delta \Delta(0)-0.2] \times 0.8$.

Substituting eqs. (10)-(12) into eq. (9) we can solve the differential equation and adjust the two constants $k_{1}$ and $k_{2}$ at each temperature so as to obtain the computed curves shown in fig. 7. The best fit for the observed segregation kinetics was obtained for any value of $k_{2}<10^{-7} \mathrm{~s}^{-1}$ in comparison with $k_{1}=(5 \pm 1) \times 10^{-4}$, independent of temperature in the range of 150 to $250^{\circ} \mathrm{C}$.

From equilibrium segregation experiments of carbon to a $\mathrm{Ni}(111)$ surface by Shelton et al. [17], the value $\Delta G_{\text {seg }}=-53 \mathrm{~kJ} / \mathrm{mol}$ was obtained. Since

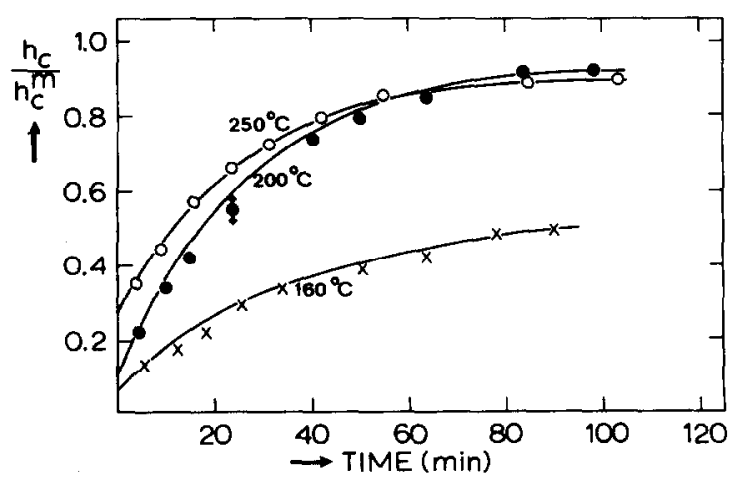

Fig. 7. Segregation isotherms of carbon to a Ni(111) surface $\left(h_{\mathrm{C}}=h_{272} / h_{\mathrm{B50}}\right.$ and $\left(h_{\mathrm{C}} / h_{\mathrm{Ni}}\right)_{\max }=$ 0.16). The temperature is indicated in ${ }^{\circ} \mathrm{C}$. The lines represent the theoretical curves as described in the text. 
$k_{1} / k_{2}=\exp \left(-\Delta G_{\text {seg }} / k T\right)$ we may, using our value of $k_{1}$ and the observed value of $\Delta G_{\text {seg }}$, calculate $k_{2}$. For $250^{\circ} \mathrm{C}$ we find $k_{2}=2.5 \times 10^{-9} \mathrm{~s}^{-1}$, in agreement with our upper limit of $10^{-7} \mathrm{~s}^{-1}$.

In addition to the developed rate eq. (9) for the segregation of bulk carbon to the surface, we were not able to describe the uptake of carbon at coverages above $0.2^{\circ} \delta \Delta$ (given in fig. 1). The small change in $\delta \Delta$ over a large period of time, compared with the carbon uptake below $0.2^{\circ} \delta \Delta$, and the lack of saturation values for $\delta \Delta$ as function of temperature made evaluation of the isotherm described by eq. (8) less accurate.

\section{4. $\mathrm{CO}$ adsorption on carburized Ni(111)}

Adsorption isotherms were measured on the $\mathrm{Ni}(111)$ crystal containing carbon coverages of $\delta \Delta=0.2^{\circ}$ (i.e. only carbon on the surface) and $\delta \Delta=0.4^{\circ}$ (i.e. carbon in deeper layers as well). The isotherms for clean $\mathrm{Ni}(111)$ will be discussed elsewhere [18]. For both surfaces the change in $\delta \Delta$ after $C O$ adsorption was taken to be proportional to the $C O$ coverage. Except for a slight shift along the $\ln (p)$ axis, no significant differences were found between the two carbon containing surfaces with respect to the observed isotherms. They were measured in the temperature range 24 to $150^{\circ} \mathrm{C}$ and $\mathrm{CO}$ pressures varying from $9 \times 10^{-9}$ to $4 \times 10^{-2}$ Torr.

Fig. 8 shows three representative isotherms with a typical curve for clean $\mathrm{Ni}(111)$ included for comparison. The adsorption was reversible causing $\delta \Delta$ to return to zero after evacuation. The carbon AES peak height remained constant with respect to the starting coverage of carbon. Contrary to the results of Bertolini and Tardy [7] and of Edmonds and Pitkethly [19], CO appeared

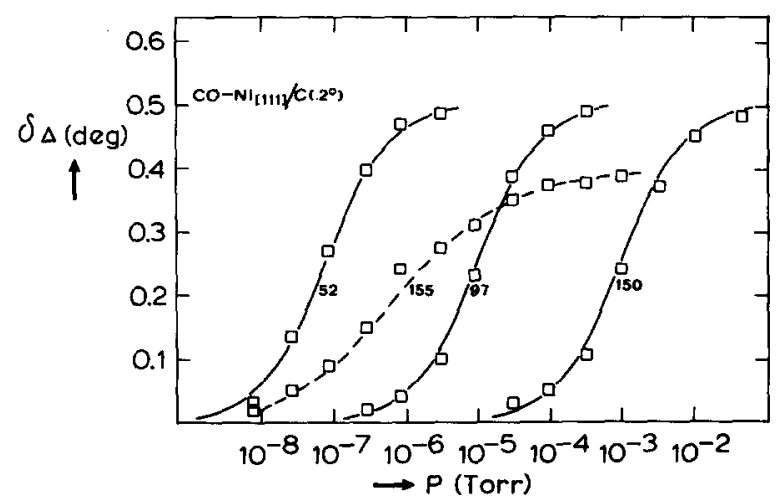

Fig. 8. CO isotherms on a clean $\mathrm{Ni}(111)$ surface (broken line) and a carbon covered $\mathrm{Ni}(111)$ surface (solid lines). The carbon coverage corresponds to $\delta \Delta_{C}=0.2^{\circ}$. Temperature indicated in ${ }^{\circ} \mathbf{C}$. 


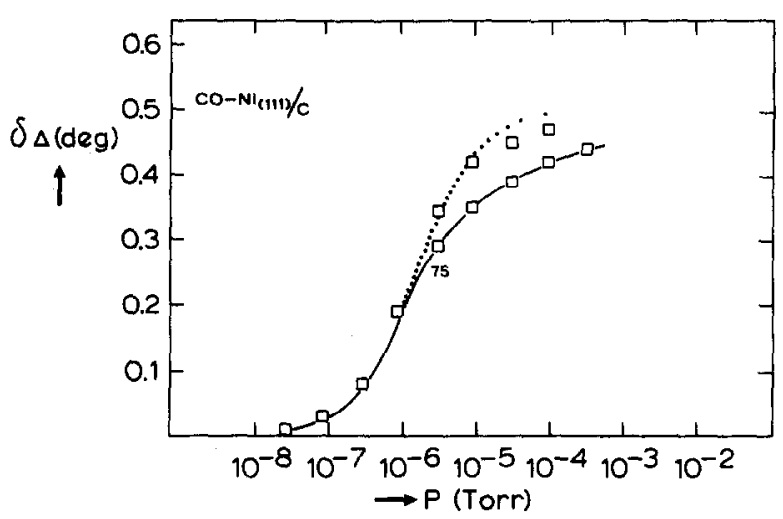

Fig. 9. Adsorption isotherm of $\mathrm{CO}$ on the carbide layer on $\mathrm{Ni}(111)\left(\delta \Delta_{C}=0.2^{\circ}\right.$ ) (dotted curve). The solid curve represents the same isotherm when a small amount of carbon is deposited from CO. Temperature indicated in ${ }^{\circ} \mathrm{C}$.

not to disproportionate on a clean and annealed Ni(111) surface [18]. Even on a carbided surface $\mathrm{CO}$ did not tend to disproportionate, only occasionally giving a small amount of extra carbon. When such a small amount of carbon was deposited by disproportionation of $\mathrm{CO}$, indicated by AES, less $\mathrm{CO}$ was adsorbed, shown in fig. 9, which was also noted by Keim et al. for $\mathrm{Ni}(100)$ [4]. The saturation value, $\delta \Delta_{\mathrm{m}}$ scattered between $0.47^{\circ}$ and $0.51^{\circ}$ independent of temperature and was, when necessary, rescaled to $0.50^{\circ}$. On a clean $\mathrm{Ni}(111)$ surface however, Gijzeman et al. [18] measured a saturation of $0.4^{\circ}$, as shown in fig. 8. Considering the fact that $\delta \Delta$ is in the same way proportional to the carbon coverage, this increase of the saturation value must be due a greater

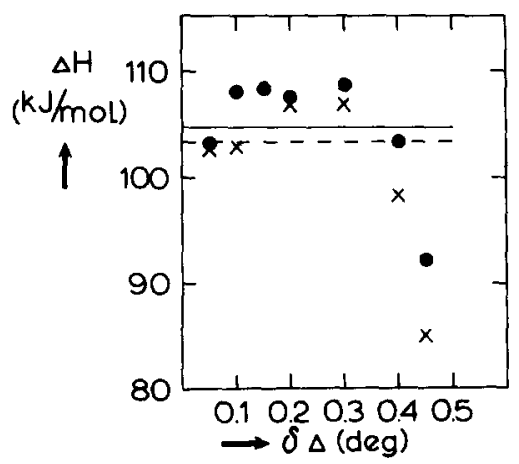

Fig. 10. Heat of adsorption of $\mathrm{CO}$ on $\mathrm{Ni}(111) / \mathrm{C}$ as a function of $\mathrm{CO}$ coverage (expressed as $\delta \Delta$ ). (e) carbon coverage of $0.2^{\circ}$ in $\delta \Delta_{C} ;(x)$ carbon coverage of $0.4^{\circ}$ in $\delta \Delta_{C}$. The solid and broken line represent the average value of the data. 
amount of $\mathrm{CO}$ adsorbed on the carbon covered surface, as compared to clean $\mathrm{Ni}(111)$.

Fig. 10 shows for both the $0.2^{\circ}$ and the $0.4^{\circ}$ carbon covered surface the isosteric heat of adsorption, which is independent of $\mathrm{CO}$ and carbon coverage and equals respectively $105 \mathrm{~kJ} / \mathrm{mol}$ for $\delta \Delta_{c}=0.2^{\circ}$ and $103 \mathrm{~kJ} / \mathrm{mol}$ for $\delta \Delta_{\mathrm{c}}=0.4^{\circ}$. For $\mathrm{CO}$ adsorption isotherms on a clean Ni(111) surface Gijzeman et al. [18] found $\Delta H=134 \mathrm{~kJ} / \mathrm{mol}$. The significant decrease of the isosteric heat of adsorption is in agreement with the results of Bertolini and Tardy [7], who measured the thermodesorption of $\mathrm{CO}$ on clean and carbon covered $\mathrm{Ni}(111)$ surfaces saturated with $\mathrm{CO}$ at room temperature. They found heats of adsorption of 125 and $85 \mathrm{~kJ} / \mathrm{mol}$ respectively.

The observed independence of the heat of adsorption as a function of the CO coverage is different from the results reported by McCarty and Madix [8] for $\mathrm{Ni}(110)$. They deposited carbon on $\mathrm{Ni}(110)$ by thermal decomposition of ethylene at $600 \mathrm{~K}$, until no further increase in the carbon AES signal was observed. From flash desorption traces, they found a $\mathrm{CO}$ binding energy of $137 \mathrm{~kJ} / \mathrm{mol}$ for a clean $\mathrm{Ni}(110)$ surface, but for a carbide covered surface the binding energy decreased from 88 to $50 \mathrm{~kJ} / \mathrm{mol}$ as the $\mathrm{CO}$ coverage increased to its maximum value.

On $\mathrm{Ni}(111) / \mathrm{C}$ the adsorption isotherms can be described according to Langmuir (fits are given as solid lines in fig. 8):

$\frac{\delta \Delta_{\mathrm{CO}}}{\delta \Delta_{m}-\delta \Delta_{\mathrm{CO}}}=A p$,

where

$A=k_{0} \exp (-\beta \Delta H)$,

$\beta=1 / k T$.

From the calculated isotherms the isosteric heat of adsorption, independent of $\mathrm{CO}$ coverage, can be evaluated. This yields $107 \mathrm{~kJ} / \mathrm{mol}$ for the surface with only surface carbon present $\left(\delta \Delta_{C}=0.2^{\circ}\right)$ and $105 \mathrm{~kJ} / \mathrm{mol}$ for $\delta \Delta_{C}=0.4^{\circ}$ (i.e. carbon in deeper layers as well), in good agreement with the isosteric heat of adsorption calculated from a direct thermodynamical analysis. The fact that the Langmuir model applies to the $\mathrm{CO}$ adsorption on a carbon covered $\mathrm{Ni}(111)$ surface shows an important difference with the $\mathrm{CO}$ adsorption on a clean surface, which has to be explained by a more complicated model [18]. The difference between the $\mathrm{CO}$ adsorption on a carbon covered and on a clean $\mathrm{Ni}(111)$ surface can be attributed to the $\mathrm{CO}-\mathrm{CO}$ interaction energy and the adsorbate surface topography. The $\mathrm{CO}-\mathrm{CO}$ interaction energy was taken to be infinite for two $\mathrm{CO}$ molecules on nearest neighbour sites on a clean $\mathrm{Ni}(111)$ surface and zero for all other sites. Since a carbon covered surface will be less smooth than a clean surface (carbon penetrates into the surface) the effective 
surface area of the crystal increases, leading to more $\mathrm{CO}$ adsorption at saturation. At the same time the distance between two possible adsorption sites increases, resulting in no repulsion between two adsorbed $\mathrm{CO}$ molecules and thus, necessarily, a Langmuir adsorption isotherm.

\section{Conclusions}

- The deposition of carbon from ethylene on a clean Ni(111) surface at $250^{\circ} \mathrm{C}$ takes place in two distinct stages. The first 0.4 monolayer of carbon is deposited on the surface, the following amount is divided among the layers just below the surface with a concentration equal to the solubility of carbon in $\mathrm{Ni}$.

- The carbon covered surface showed no clear LEED pattern.

- At a crystal temperature of $250^{\circ} \mathrm{C}$ the reaction of oxygen with surface carbon exhibits a reaction rate that is first order in the oxygen pressure and independent of carbon coverage. The reaction probability is an order of magnitude larger than for the same reaction on a $\mathrm{Ni}(100)$ surface, and equals $6 \times 10^{-2}$ carbon atoms removed from the surface per incident oxygen atom at $250^{\circ} \mathrm{C}$.

- After removal of the surface carbide with oxygen, segregation of carbon takes place, being satisfactorily described by a McLean model.

- Reversible CO adsorption isotherms on surfaces with a carbon content of $0.2^{\circ}$ and $0.4^{\circ}$ in $\delta \Delta$, appeared not to differ greatly, confirming the carbon content above $0.2^{\circ}$ in $\delta \Delta$ to be situated beneath the surface. The isotherms obey the simple Langmuir equation. The isosteric heat of adsorption, which was independent of $\mathrm{CO}$ coverage, was lowered by the presence of surface carbon to a value of about $105 \mathrm{~kJ} / \mathrm{mol}$, which is about $30 \mathrm{~kJ} / \mathrm{mol}$ less than on the clean Ni(111) surface. Both on a clean and a carbon covered Ni(111) surface $\mathrm{CO}$ did not disproportionate. Because of the increase of the surface area by the presence of carbon, more $\mathrm{CO}$ can be adsorbed than on a clean surface.

\section{Acknowledgement}

The investigations were supported by the Netherlands Foundation of Chemical Research (SON) with financial aid from the Netherlands Organisation for the Advancement of Pure Research (ZWO).

\section{References}

[1] J.C. Bertolini and G. Dalmai-Imelik, Colloq. Intern. CNRS 187 (1969) 135.

[2] M.G. Cattania, M. Simonetta and M. Tescari, Surface Sci. 82 (1979) L615. 
[3] S. Lehwald and H. Ibach, Surface Sci. 89 (1979) 425.

[4] E.G. Keim, F. Labohm, O.L.J. Gijzeman, G.A. Bootsma and J.W. Geus, Surface Sci. 112 (1981) 52.

[5] F. Labohm, C.W.R. Engelen, O.L.J. Gijzeman, J.W. Geus and G.A. Bootsma, Surface Sci. 126 (1983) 429.

[6] R. Sau and J.B. Hudson, Surface Sci. 102 (1981) 239.

[7] J.C. Bertolini and B. Tardy, Surface Sci. 102 (1981) 131.

[8] J.G. McCarty and R.J. Madix, Surface Sci. 54 (1976) 121.

[9] P.R. Webber, C.E. Rojas, P.J. Dobson and D. Chadwick, Surface Sci. 105 (1981) 20.

[10] M.P. Seah, Surface Sci. 32 (1972) 703.

[11] M.P. Seah and W.A. Dench, Surface Interface Anal. 1 (1979) 1.

[12] K. Natesan and T.F. Kassner, Met. Trans. 4 (1973) 2557.

[13] F. Labohm. O.L.J. Gijzeman and J.W. Geus, Surface Sci. 135 (1983) 409.

[14] P.H. Holloway and J.B. Hudson, Surface Sci. 43 (1974) 141.

[15] C.M.A.M. Mesters, A.F.H. Wielers, O.L.J. Gijzeman, G.A. Bootsma and J.W. Geus, Surface Sci. 117 (1982) 605.

[16] J.M. Blakely and J.C. Shelton in: Surface Physics of Materials, Vol. I (Academic Press, London, 1975) p. 189.

[17] J.C. Shelton, H.R. Patil and J.M. Blakely, Surface Sci. 43 (1974) 493.

[18] O.L.J. Gijzeman, M.J. van Zandvoort, F. Labohm, J.A. Vliegenthart and G. Jongert, J. Chem. Soc. Faraday II, to be published.

[19] T. Edmonds and R.C. Pitkethly, Surface Sci. 15 (1969) 137. 